\title{
TERAPIA BASADA EN LA MENTALIZACIÓN: ALGUNAS IDEAS SOBRE LAS ADICCIONES, EN TORNO AL CASO DE LENA ${ }^{1}$
}

\author{
Juan Domingo Martín Fernández ${ }^{2}$ \\ Vinaròs (Castellón)
}

\begin{abstract}
El artículo plantea un caso clínico de patología dual grave tratada en Unidad de Conductas Adictivas (desintoxicación y deshabituación ambulatoria en salud mental pública), de adicciones tóxicas en una estructura límite de personalidad, como marco general para trazar distintas ideas que convergen en la Terapia Basada en la Mentalización (MBT), desarrollada en las últimas décadas por el equipo de Peter Fonagy \& Mary Target en el Anna Freud Center de Londres. Se desarrollan distintos planteamientos coherentes con este marco, por parte de la Teoría de la Mente (Psicología Cognitiva y del Desarrollo), el apego (estilos educativos parentales) y el Psicoanálisis Contemporáneo (autores relacionales como Ferenczi, Fairbairn, Pichón Rivière, Winnicott, Bollas, Kohut, Mitchell y los intersubjetivos), con apuntes relativos al contexto de las adicciones y concluyendo con algunas aportaciones personales de los investigadores de la MBT.
\end{abstract}

Palabras clave: Peter Fonagy, Mary Target, mentalización, adicciones, trastorno límite de la personalidad, narcisismo, relacional, espejamiento.

This paper exposes a clinical case of serious dual-pathology which has been tryed at Unity of Addictive Behaviours (ambulatory detoxification and personal unhabit at public mental health), about toxic addictions into a borderline personality structure. This serves as a general framework to draw different issues which converge into Mentalization-Based Treatment (MBT), that has been developed for decades by Peter Fonagy \& Mary Target's team at Anna Freud Center in London. Several approaches adequate to this framework are developed, from the Theory of Mind (Cognitive and Developmental Psychology), the Attachment (parental educational styles) and the Contemporary Psychoanalysis (relational people like Ferenczi, Fairbairn, Pichón Rivière, Winnicott, Bollas, Kohut, Mitchell and the intersubjective authors), with notes about the addictions context and concluding with the personal contributions of MBT researchers..

Key Words: Peter Fonagy, Mary Target, mentalization, addictions, borderline personality disorder, narcissism, relational, mirroring.

English Title: MENTALIZATION BASED THERAPY: SOME IDEAS ABOUT ADDICTIONS, IN THE CASE OF LENA

\section{Cita bibliográfica / Reference citation:}

Martín Fernández, Juan Domingo. (2019). Terapia basada en la Mentalización: Algunas ideas sobre las adicciones en torno al caso Lena. Clínica e Investigación Relacional, 13 (1): 223-242. [ISSN 19882939] [Recuperado de www.ceir.info ] DOI: 10.21110/19882939.2019.130114

\footnotetext{
${ }^{1}$ El artículo transcribe una de las sesiones clínicas impartidas por el autor en la Sección de Salud Mental del Hospital Comarcal de Vinaròs, en enero de 2019. La información ofrecida se adecua a la confidencialidad necesaria en la transmisión profesional de material clínico y cuenta con la pertinente autorización.

2 Psicólogo Clínico y Máster en Psicoanálisis Relacional, en la actualidad trabaja en la Unidad de Conductas Adictivas (UCA) de Vinaròs (Castellón), de la Agencia Valenciana de Salud. Contacto: juandomismo@yahoo.es
} 


\section{CASO LENA:}

Mujer de casi 32 años, natural y residente en la zona, en seguimiento en nuestra UCA de Vinaròs desde los 18 años (en 2005); en terapia conmigo desde 2014 (año de mi incorporación a la plaza). De acuerdo a las notas de la historia clínica de papel y diferentes documentos consultados para la sesión clínica -a menudo desordenados, informes de distinta procedencia y cotejo con apuntes propios-, la paciente se inició en el consumo de tabaco y alcohol a los 12 años, en el cannabis a los 13 (diario desde los 15), en la cocaína, speed, anfetaminas y éxtasis a los 15 también (ocio de los fines de semana, con alcohol), y años más tarde consumo de heroína -fumada y esnifada, mezclada con otras drogas- a los 26, aprox. Lena dejó los estudios con 16 años, en $2^{\circ}$ de la ESO, optando luego por trabajos muy precarios, erráticos, y sobre todo actividades marginales, entre ellas la prostitución hace 2 ○ 3 años, en Valencia. Tiene reconocida una PNC (pensión no contributiva) por discapacidad del 73\%, de la cual ella siempre se ha administrado el dinero, y hace un año fue inscrita por los Servicios Sociales de la localidad en un curso remunerado de administrativo, donde las condiciones de asistencia eran relativamente exigentes (horarios madrugadores, puntualidad, presencia, exposiciones), y a Lena le costaba bastante cumplir. Mostraba esfuerzo, también motivada por el incentivo económico, pero había días que no acudía a clase, y ésta era también una de las razones para asistir con más frecuencia y compromiso a las citas médicas y psicológicas, que justificaban la ausencia de clase ese día. Posteriormente ingresó voluntariamente en un centro de día para rehabilitación de tóxicos, con horarios poco compatibles con el curso de administrativo, sin perder la plaza gracias a una ILT (baja médica).

Respecto al entorno de Lena, la familia se caracteriza por su carencia de estructura. Los padres de la paciente eran toxicómanos antes y durante su infancia, y ambos ya están fallecidos. Ella fue acogida por la abuela materna, que también ha sido la persona que ha criado a una hermana 14 años menor, de un padre diferente (éste se encuentra vivo, también era toxicómano, fue presidiario, en la actualidad visita ocasionalmente a la familia, sobre todo a su hija, la hermana de Lena que ahora tiene 18 años). Por tanto, desde el nacimiento la tutela de la paciente ha estado con los abuelos maternos, que actualmente cuentan con 68 años la mujer y 64 el marido (este hombre puede no ser el abuelo biológico de Lena, según una referencia de un informe de la historia clínica, y es la persona sobre la que actualmente ella deposita más hostilidad y rechazo). La abuela es quien siempre se encarga de acompañar a Lena a los dispositivos, la ha rescatado en numerosas ocasiones de sitios hostiles y caóticos, ha supervisado muchas veces tratamientos y medicaciones, gestionado citas y visitas... es la principal figura de apego de la paciente, sin duda. 
Los padres, como se ha dicho, están fallecidos desde hace muchos años: el padre cuando Lena tenía 12 años, y la madre cuando cumplía 18 aprox. (la madre en aquel momento tenía 37 años, tuvo muchas fases de consumo y rehabilitación frustrada, finalmente un accidente de moto y agonía en la $\mathrm{UCI}$ ). Del padre consta que muchas veces prometía visitar a su hija, y ésta esperaba con la abuela su venida, pero no se presentaba. Lena quedaba decepcionada y abandonada, pese a la presencia de la abuela. La madre hacía su vida fuera de casa, de manera errática, con distintos compañeros y sin apenas comunicación con la hija; cuando falleció, Lena se encontraba ingresada por vez primera en un centro de día, ya con adicciones graves a muchos tóxicos.

Desde entonces, esta paciente ha utilizado numerosos dispositivos y recursos de tratamiento, además de nuestra UCA (desintoxicación y deshabituación ambulatoria), a saber: UDH (desintoxicación hospitalaria) al menos 6 veces, CD y CT (centros de día y residenciales) de varias fundaciones, públicas y concertadas, con diferentes tipos de estancias (entre semanas y meses), alguno de ellos específico para mujeres, otros para perfiles característicos de la patología dual (trastorno mental grave + adicciones), también comunidades evangelistas (Betel) donde el ingreso es inmediato y gratuito, sin asistencia médica para desintoxicación autónoma "por las bravas", sostenida por un entorno de apoyo social, religioso y ocupacional (la paciente no tiene creencias religiosas destacadas, es escéptica). En la actualidad acude a nuestra UCA, con seguimiento irregular y a veces instrumental, y al centro de día de la localidad -recientemente abierto, concertado- por los consumos actuales de cocaína y speed, además de la Unidad de Salud Mental.

Lena está diagnosticada de dependencia a cocaína, heroína, anfetamina, alcohol y tabaco; no tiene consumos de cannabis, por ejemplo, "porque le sientan mal". Tiene diagnóstico compatible y dual con un Trastorno Límite de Personalidad (TLP), con rasgos antisociales y también bipolares (grandes cambios de humor, bruscos, no ligados estrechamente a objetos o vínculos aparentes). Los tratamientos médicos se los prescribe su psiquiatra de referencia y el médico de nuestra UCA -en este caso Suboxone, agonista parcial para la desintoxicación autónoma de la heroína-, aunque la toma de la paciente es habitualmente desordenada y con variaciones espontáneas (como en la inmensa mayoría de estos casos graves de TMG + adicciones).

Las principales identificaciones de la paciente, por consiguiente, son su abuela materna y la hermana -ahora mismo más importante y referencial que la abuela-, ninguna de ellas consumidora ni patológica. También tiene un amigo / ex-pareja, consumidor como ella, pero apoyo emocional, que la visita a temporadas, y otras ella se muda con él a la ciudad. La principal figura de enfrentamiento y hostilidad es el abuelo, quien en el pasado 
alguna vez visitó los recursos y colaboró en la coordinación del caso, pero hace ya muchos años que no se presta a nada. La paciente muestra crecientes paranoias con este hombre, a quien acusa de los problemas de salud de su madre, llega a dudar de su orientación sexual y teme de él conspiraciones en su contra, para enfrentar a la paciente con la hermana y abuela. En la actualidad Lena ha vuelto a vivir con su amigo, reincidiendo en los consumos de alcohol y cocaína, con frecuencia varias veces a la semana, tras dos meses aprox. de cierta contención, según venía refiriendo.

Una característica destacable de esta paciente es la conciencia de autodestrucción que muestra, pues ella misma verbaliza seriamente los problemas que tiene: trastornos, dinámicas tóxicas y enfermizas, expresando un discurso crítico hacia las drogas, con esfuerzo de deshabituación; pero a la vez recae voluntariamente en los consumos al cabo de un tiempo, al sentir de nuevo el vacío y la melancolía característica del grave TLP que padece, y el desarraigo arrastrado toda su vida. Los deterioros orgánicos están apareciendo desde hace varios años, con crisis serias de salud, intoxicaciones, alguna sobredosis, síntomas disociativos, infecciones, pérdidas cognitivas, y sobre todo rasgos de personalidad más paranoides, antisociales, también depresivos. Sin embargo, las temporadas que contiene los consumos, frena la escalada, colabora y se relaciona más con el entorno familiar y con los dispositivos terapéuticos, muestra una buena base de cooperación, sintonía, ternura, afecto... en definitiva, self vital.

He querido presentar primero el caso clínico para luego enmarcar el desarrollo de la sesión, no tanto con el objeto de analizar pormenores y escenas de Lena, sino como punto de partida para que los lectores puedan tener en mente un caso grave de adicciones + TLP (como tantos otros accesibles en la clínica diaria) a la hora de comprender las aportaciones de la Terapia Basada en la Mentalización de Peter Fonagy y su equipo (MBT, MentalizationBased Treatment). La cual intentaré a continuación describir y relacionar con la casuística de las adicciones, y todo ello desde una perspectiva psicoanalítica relacional.

\section{MENTALIZACIÓN:}

Simplemente es el nombre que recibe "la capacidad cognitiva de interpretar el comportamiento propio y el de los otros accesibles a los sentidos, a través de la atribución de estados mentales". Consiste básicamente en "saber leer" lo que piensa, siente o cree otra persona, en función de lo que vemos que está haciendo o cómo se está comportando en un contexto dado; y del mismo modo enjuiciar la respuesta del otro hacia nosotros por 
lo que ve o percibe de nuestra conducta, y el estado mental que puede estar atribuyéndonos por ello.

Por tanto, no se trata sólo de observar y juzgar conductas, sino de "adivinar" las ideas propias y ajenas acerca de las creencias, sentimientos, actitudes, deseos... (todas las variables subjetivas) que están subyaciendo a una conducta concreta observada en ese momento. Implica la comprensión reflexiva de las experiencias y actuaciones de uno mismo y de los otros, y por consiguiente entender la naturaleza de lo mental: la representación cognitiva difiere de la realidad observada fuera, por una multitud de factores que se aprehenden de manera automática e inconsciente (pero se pueden hacer conscientes, de una forma metacognitiva, pensando sobre ello).

En definitiva, una mentalización eficaz sirve a 3 constructos fundamentales: la orientación y el control de toda clase de comunicación interpersonal y configuración de vínculos; la regulación de las propias emociones -autorregulación- y conductas autocontrol-; y una mayor competencia emocional y social del sujeto.

\section{PETER FONAGY Y LA MBT - MENTALIZATION-BASED TREATMENT:}

Peter Fonagy es un psicólogo y psicoanalista británico de origen húngaro (nació en Budapest en 1952), residente en Londres, académico de la University College London donde estudió Clinical Psychology, y actualmente ejerce como Catedrático de Psicología y Ciencias del Lenguaje, Profesor de Psicoanálisis Contemporáneo y Ciencias del Desarrollo, Director de la Unidad Psicoanalítica para estudiantes de Doctorado y Coordinador del Anna Freud Center de Londres. Es la persona que ocupa la Freud Memorial Chair en la misma UCL.

Junto a colegas como Mary Target, Anthony Bateman y otros, Fonagy ha desarrollado en las últimas décadas investigaciones en torno al Psicoanálisis Contemporáneo, en constante diálogo y colaboración con la Psicología Cognitiva y las terapias basadas en la evidencia, en niños y adultos, especializándose en el campo de las patologías narcisistas y los TLP. Es autor principal de la Mentalization-Based Treatment, una propuesta experimental validada de psicoterapia analítica -y relacional, podemos decir abiertamente- que también se está testando y adaptando a diferentes poblaciones y contextos: infancia (MBT-C), familias (MBT-F), adolescentes (MBT-A), y la última versión integradora del campo múltiple y complejo de la juventud, el llamado AMBIT: Adaptive Mentalization-Based Integrative Treatment. Todas las investigaciones y aplicaciones originales se han desarrollado en el Anna Freud Center de Londres (psicoanálisis académico, por tanto). 
Los autores definen a la MBT como una síntesis integradora de 3 componentes, que veremos por separado exponiendo al tiempo algunos apuntes particulares: Teoría de la Mente + Apego + Psicoanálisis Contemporáneo.

\section{TEORÍA DE LA MENTE:}

Se trata del nombre que recibe el constructo cognitivo de la mentalización, ya mencionado más arriba: la capacidad mental de los sujetos de atribuir pensamientos e intenciones a otras personas (o entidades simbólicas y virtuales). Un vídeo de Antonio Block en Youtube lo explica estupendamente en 8 minutos: se le pregunta a niños de 4-5 años qué creen que contiene una hucha con forma de cerdito, y éstos responden que dinero (aciertan); luego delante de ellos se vacía la hucha de las monedas y se rellena con canicas, y se les vuelve a preguntar qué contiene ahora; respondiendo correctamente que canicas. Sin embargo, si se les interroga a los mismos niños qué contestarían otros iguales que entraran en ese momento y vieran la hucha cerrada, muchos fallan respondiendo que canicas, en lugar del dinero que intuitivamente van a pensar que contiene. También lo ilustran con el ejemplo de comprar regalos, cuando una niña de 6 años ya es capaz de pensar los gustos y preferencias de su amigo que cumple años, y regalarle algo que le gusta a él -y explicar por qué-, y no lo que realmente le gustaría a la niña para sí.

En definitiva, son ejemplos análogos a la clásica ilustración de las niñas "Sally \& Anne" de los libros de Psicología, donde en viñetas se explica la historia de Sally, que tiene una cesta, y Anne que tiene una caja: Sally guarda una canica en su cesta, y después de que se haya ido Anne cambia la canica de la cesta de Sally a su propia caja; cuando vuelva Sally, ¿dónde buscará su canica? ¿en la cesta donde la dejó, o en la caja donde sabemos nosotros que ahora está?

La teoría de la mente tiene sus orígenes en Gregory Bateson (1904-1980), antropólogo, lingüista, científico social y psicólogo, autor del doble vínculo y de la teoría de la comunicación junto con Watzlawick. Ellos decían que toda mente -humana, animal o artificial- se define por 3 propiedades emergentes de los procesos: aprendizaje, memoria y toma de decisiones.

Esta capacidad de cognición y metacognición humana no es una facultad aprendida, a pesar de la influencia ambiental moduladora (variables familiares, fraternales, escolares, etc.); sino que es congénita, innata, activada a partir de los 3-4 años de vida normalmente antes de los 6 - según la estimulación eficaz ambiental, y constatada en todas las culturas de la Tierra (luego es universal). Jamás ningún animal -chimpancé, delfín, perro- 
ha superado las pruebas de la Teoría de la Mente que logran los niños de cualquier cultura humana a los 6 años. Sin este constructo cognitivo y vivencial no sería posible la vida en sociedad ni la autonomía de las personas.

De hecho, la deficiencia en el desarrollo cognitivo de la Teoría de la Mente está asociada a patologías graves, cualitativas (espectro autista, demencias) y cuantitativas (psicosis y patologías narcisistas, como TLP y adicciones). A nuestros pacientes graves de UCA, como Lena, les cuesta mucho "mentalizar", situarse en la mente de otras personas y pensar, razonar o decidir como hacen los otros, en base a los datos que conocen. El pensamiento egocéntrico -narcisista- es habitual, en distintos grados, y la empatía de la persona muchas veces es consecuencia del grado en el que puede concebir mentalmente al otro, sus reacciones y sus estados cognitivos.

\section{TEORÍA DEL APEGO:}

No es mi intención repasar los conceptos y aplicaciones prácticas de los distintos tipos de apego, seguro e inseguro (ansioso/ambivalente, evitativo, desorganizado), sino llamar la atención sobre esta importante variable a encuadrar para situar la posición del analista en la terapia, sobre todo respecto al ESTILO EDUCATIVO recibido / implantado en el paciente. Éste resulta a la postre fundamental para comprender su actitud respecto a los consumos y las adicciones, y la manera como mejor puede él reconocer las pautas y recibir la psicoeducación en esta faceta clínica; lo cual, además, se puede extender a muchos aspectos y escenas del tratamiento: comunicaciones, afectos, recuerdos, transferencias, enactments, etc.

Se pueden clasificar 4 tipos de estilos educativos o parentales, de los cuales el último es el más funcional. Veamos sus características básicas:

1.-SOBREPROTECTOR: mucho afecto y poco control. Padres muy responsables de los hijos, a los que protegen de antemano, no delegan en ellos ninguna decisión importante porque en el fondo creen al hijo/a siempre inmaduro, que no sabe ni puede decidir por sí mismo, que se va a equivocar seguro y va a sufrir; y es labor de los progenitores evitarle estos errores. Estos padres (es decir, alguno de ellos, la dinámica frecuente y predominante en la familia) sienten mucha culpa, quieren supervisarlo todo, tienen mucho miedo a fracasar y hacer daño; en consecuencia, buscan manejarse por pautas, unas que continuamente están dando a los hijos y otras que demandan frecuentemente de los profesionales, y la reacción habitual consiste en meter miedo al otro, castigar la iniciativa del hijo/a elogiando sólo las conductas dependientes hacia ellos. Los hijos suelen 
desenvolverse de forma heterónoma, miedosa, dependiente, y ante todo despreocupada: están acostumbrados a que "otros me lo resolverán", y apenas se movilizan, ni deciden, ni cambian.

2.-AUTORITARIO: mucho control y poco afecto. Padres que creen que ellos tienen siempre la razón, y además la autoridad para imponerla por los medios que sea necesario; no llegan a empatizar con los hijos, con la diferencia o la alteridad. Los padres deciden por el resto, castigan y a veces lo hacen con furia; crían hijos sumisos, que atienden sólo a los defectos, errores, exigencias, con grandes dosis de intolerancia, incomprensión del otro, ingratitud (porque en la familia no se valora el cumplimiento del deber, que se toma como normal, nada extraordinario). El hijo/a suele devenir ansioso, con mucha culpabilidad, mentiras, frecuentemente rencoroso y pasivo-agresivo, evitativo, dependiente del control externo y acostumbrado a saltarlo cuando la autoridad no está presente o no se entera.

3.-NEGLIGENTE O PERMISIVO: poco control y poco afecto. Estos padres suelen dejar que los hijos "se críen solos", "aprendan pronto lo dura que es la vida", y sienten poca preocupación ante dilemas o situaciones de los menores porque "ya se apañarán"; los padres confían mucho en la iniciativa y autonomía del hijo/a, hasta el punto de enfadarse cuando éstos les reclaman atención, pautas o se muestran dependientes hacia ellos, o cuando por un modo $u$ otro molestan. Los progenitores en realidad atienden poco al hijo/a, lo elogian poco, le castigan sólo cuando interfiere con sus hábitos y gustos -cuando cansa, de modo que éste queda expuesto a otras influencias, positivas y negativas. Los hijos se desarrollan en efecto autónomos, pero también inseguros, propensos a conflictos personales y/o sociales, principalmente cuando chocan con límites o normas externas (contexto laboral, escolar, sentimental), y suelen buscar apoyo en figuras de autoridad, que le llevan a desculpabilizarse y evadirse de responsabilidades grandes, asumiendo pocos riesgos.

4.-DEMOCRÁTICO: control equilibrado y mucho afecto. Estos padres sí comprenden al hijo/a que están criando, la fase de su desarrollo, los problemas y pensamientos que tiene (buena Teoría de la Mente, por tanto); saben que él necesita modelos eficaces de aprendizaje, modelado de ensayo-error que fomente los criterios propios del hijo/a, las discrepancias del modelo, la independencia y la identidad propia frente al ejemplo o norma parental. Los padres democráticos están satisfechos cuando los hijos cumplen las instrucciones y mandatos, pero también cuando expresan sus gustos y deseos, aunque sean contrarios a lo esperado; refuerzan progresos y elementos positivos de la conducta, elogian los esfuerzos, castigan aspectos inaceptables y dañinos, pero ignoran al mismo tiempo los pequeños errores y fallos, para prevenir el fracaso; y si éste ocurre, nunca lo 
atribuyen a la persona global de su hijo/a sino a la conducta llevada a cabo, parte de la experiencia de la vida (muestran paciencia activa con ellos). Los hijos a priori suelen desarrollarse con apego seguro, identidad propia y más madura, autocontrol, capacidad de iniciativa y emprendimiento, satisfacción de deseos, responsabilidad de los actos a la par que búsqueda de sensaciones y riesgos; lo cual le puede llevar a experimentar directamente con los límites, con los peligros para decidir por sí mismos, y también caer -o no, voluntaria o involuntariamente- en el mundo de las adicciones.

En definitiva, la conclusión del estilo educativo democrático, llevado a cabo por los padres en la infancia y crianza de los hijos, y ejemplificado por el analista relacional en el proceso terapéutico, se resume en estos 7 principios: sensibilidad, comprensión, responsabilidad, optimismo, tolerancia, aprendizaje, respeto.

\section{PSICOANÁLISIS CONTEMPORÁNEO:}

Vayamos ahora brevemente recorriendo algunas ideas de autores postfreudianos, relacionales, que recoge la MBT en su abordaje genérico con TLP, y específicamente el trato con pacientes adictos como Lena, y que constituye gran parte del bagaje teórico y práctico a trabajar en nuestro dispositivo de la UCA:

SÁNDOR FERENCZI (1873-1933): Gran defensor de la teoría traumática de la neurosis, aunque ésta hubiera sido abandonada -y denostada- por el maestro Freud en favor de la teoría estructural de la fantasía. Ferenczi se atrevió a asegurar que siempre se podían rastrear traumas infantiles detrás de cada síntoma neurótico o psicótico, y que el empeño de atribuir estos traumatismos exógenos a factores constitucionales intrapsíquicos -como la compulsión a la repetición- era en sí mismo un acto sádico y encubridor de los abusos, que traía consigo la retraumatización del sujeto. Una crítica rotunda y radical al Psicoanálisis ortodoxo, que desde entonces marca el devenir del paradigma relacional.

Ferenczi pensaba que no eran tanto los deseos incestuosos del bebé (el descubrimiento primigenio de Freud, la sexualidad infantil), sino las acciones incestuosas de los progenitores sobre el cuerpo y la mente indefensas del bebé -camufladas e intelectualizadas como muestras de ternura- las causantes de la génesis del síntoma; el cual además concebía como una voluntad de no-ser del sujeto para ser aquello que demandaban o necesitaban los demás del entorno.

En efecto, este autor categorizó la libido en dos tipos antagónicos: el "impulso de hacerse valer" (que lleva a la autonomía, el ser genuino, lo que autores posteriores llamarán "verdadero self") versus el "impulso de conciliación" (la adaptación a los objetos, el ser para 
otro, el no-ser o "falso self" en otra terminología). El antagonismo oposicionista entre los dos causaba la patología de la psique, el sufrimiento del menor, el trauma infantil; por contra la triangulación -como el diálogo entre los principios del placer y la realidad freudianos- hallaba una solución de crecimiento y elaboración en el desarrollo psicosexual del bebé, dentro de su contexto cultural y familiar. El bebé para Ferenczi es siempre un ser hambriento, voraz, devorador de todo, fácilmente "envenenado" por contenidos narcisistas, dependientes o sumisos.

Suyas fueron dos aportaciones fundamentales que desde entonces han marcado el desarrollo psicoanalítico: la identificación con el agresor -en otras corrientes atribuida a Anna Freud- y la confusión de lenguas. Ambas constituyen el principio del síntoma psíquico, tanto neurótico como psicótico: la defensa básica del infante de sufrir menos justificando parte del abuso que recibe, identificándose con su agresor, introyectando la agresión como natural o incluso moral, punto necesario de la educación, el cariño de los padres o las normas sociales; lo que a su vez contribuye a perpetuar los abusos, cuando se subestima su poder dañino y se contemporiza con el valor afectivo o pedagógico, justificándolo de alguna manera en las buenas intenciones o alguna clase de derecho. El menor sufre menos cuando parte del mal que recibe lo acepta, lo relativiza, incluso llega a aliarse con ello y normalizarlo como justo, o reproducirlo contra otros indefensos como él.

La confusión de lenguas es el correlato de esta dialéctica perversa: aquel conflicto entre dos partes asimétricas, donde una daña a la otra queriéndose en el canal y en el mensaje comunicar, pero no hallando el mismo código para ser correctamente interpretado; cuántos afectos de los padres son invasivos para el niño/a, ofensivos y persecutorios para el adolescente, sin que provengan de una mala fe o sentimiento de odio, sino que simplemente han sido mal expresados, mal comunicados, mal interpretados, como dos personas que se hablan en lenguas diferentes y entienden del otro lo opuesto a lo que nos quiere transmitir. Los síntomas, defensas del inconsciente contra algún abuso o ataque, no tienen por qué ser huellas de abusos perversos continuados, sino respuestas de confusión ante la ambivalencia en que llegan a incidir los afectos del otro en mi propio Yo, y la difusa raya que separa la ternura cariñosa de la sobrecarga libidinosa, invasiva.

RONALD FAIRBAIRN (1889-1964): Psicoanalista escocés, teórico de las relaciones objetales, las llega a concebir casi como primarias a la pulsión, de modo que no es posible entender ésta sin las primeras: "la pulsión es una estructura psíquica en acción", luego "la pulsión no busca la descarga, sino al objeto desde el principio"; esto es, a la madre. 
Es importante esta cualidad relacional de la pulsión primaria, biológica, que mueve al Yo temprano a buscar continuamente el objeto materno. Para Fairbairn este Yo central se encuentra originalmente disociado en múltiples "yoes", cada uno de ellos identificado con objetos parciales, unos antilibidinales o persecutorios (más primitivos y tempranos), otros libidinales y gratificantes (más posteriores, maduros). Los antilibidinales actúan como "saboteadores internos" que canalizan la agresión hacia dentro, como carencia de necesidades insatisfechas y rechazo al abandono de la madre; el Yo es por consiguiente la instancia represora que ataca al objeto interno -a sí mismo, en clave melancólica-, mientras que al externo -la madre real- lo idealiza para mantenerlo a salvo porque sigue siendo vital para la supervivencia del Yo, para seguir viviendo. El otro se protege a costa de acusarse uno a sí mismo, de atacarse uno a sí mismo, como en tantas conductas adictivas.

Nace así la dialéctica del apego a los objetos dolorosos y la culpabilidad masoquista, repleta de conductas de escape; Fairbairn decía que "era preferible ser uno malo en un mundo presidido por Dios, que bueno en un mundo liderado por el diablo". Es más coherente y adaptativo conservar la idealización del orden externo, natural, "justo" (recordemos aquí la identificación con el agresor recién vista), y acusarse uno mismo del fallo y el síntoma, que hacerlo al revés, por mucho que el narcisismo y el victimismo dramático del paciente muchas veces lo quiera camuflar; las dinámicas inconscientes, represoras, masoquistas juegan en sentido contrario. Los consumos compulsivos de tóxicos son una muestra conductual de esta dialéctica autodestructiva, "saboteadora interna".

ENRIQUE PICHÓN RIVIĖRE (1907-1977) es el autor que mejor sintetiza la "situación depresiva básica": la de saberse en la tierna infancia rechazado por tu figura de apego, por tu objeto materno, no amado por cómo uno es, libre, sino decepcionado; y la consiguiente necesidad de "ganarse" el afecto condicional de esta figura -su atención, amor, aprobación, significación- a través de defensas neuróticas, construcciones, síntomas e imágenes que en el fondo no hacen otra cosa que tapar al exterior este vacío y fragmentación interiores.

Se trata del fondo meláncolico que constituye la estructura genérica de las adicciones, también de las psicosis y las patologías límite -el caso de Lena es más que representativo-, y que ilustra estos grandes sufrimientos como evasiones del vacío, voracidad de objetos con evacuación continua, relaciones anaclíticas de apego fusional a auténticas sombras que no sostienen más que la imagen depresiva de uno mismo, abandonado, solo, tóxico.

DONALD WOODS WINNICOTT (1896-1971): Generaliza la antigua idea de Ferenczi de los impulsos de hacerse valer y conciliación, con los nombres de "verdadero" versus "falso self"; 
y además establece por vez primera que el análisis terapéutico no debe entenderse como un juego cerrado de reglas y técnicas predeterminadas (un juego - game), sino como un espacio abierto, transicional, bastante simétrico, donde las reglas o normas se van estableciendo durante el transcurso, van cambiando según las interacciones entre los participantes (el jugar - play). El juego analítico, dentro del paradigma relacional que este autor promociona sin nombrarlo así -sin pretenderlo seguramente-, se convierte en un fenómeno transicional en sí mismo, creativo, emergente, negociado, lleno de vivencias compartidas. El fenómeno lo caracteriza la mutualidad, la reciprocidad...; las técnicas son más apuestas (interpretación, esclarecimiento) que certezas, recetas o pautas hechas.

Winnicott también es el analista que clasifica las tres funciones maternales de la figura de apego sobre el infante: holding, handling y object-presenting; respectivamente sostener, erotizar (manoseando la madre, con palabras afectuosas el terapeuta, y algún abrazo) y presentar objetos, en el acompañamiento espontáneo al niño mientras éste asimila los límites y frustraciones de la realidad. Estas tres funciones, tan estancadas y subdesarrolladas en el proceso de crianza del sujeto -por las carencias de sus figuras de apego o cualquier otra circunstancia traumática-, deben ser repetidas por el analista en el transcurso de la terapia, como una oferta de re-desarrollo de capacidades nunca antes explicitadas al paciente, y ahora materializadas sesión a sesión por medio de la comunicación verbal y no verbal, y la aceptación honesta, positiva e incondicional.

Una de las claves fundamentales de la terapia va a residir en cómo actuar ante la omnipotencia narcisista del otro -del paciente en este caso-, que trabajando con adictos recuerda tanto al egocentrismo del niño pequeño: quiere hacer lo que le da la gana en cada momento, y se ofende con cada limitación o confrontación que se le opone. Winnicott decía que la omnipotencia narcisista del otro había que preservarla durante mucho tiempo como variable positiva de la transferencia, mientras se afianza el vínculo terapéutico y la tolerancia del sujeto con el analista, y éste es paulatinamente capaz de ayudarle a asimilar las frustraciones del medio exterior adoptando los recursos y estrategias eficaces para este aprendizaje.

Para ello, y esto es sustancial, el terapeuta puede -incluso debería- dejarse manipular por el paciente, dejarse utilizar, atacar, hasta destruir en ese juego-play del análisis, sin llegar nunca a sucumbir ni a retaliar -a vengarse con otras interpretaciones a degüello, o devoluciones calientes y saturadas-, sino limitarse a sobrevivir, sostenerse, perdonar, comprender al otro, ayudarlo, justificarlo también...; en definitiva seguir jugando con él con estas nuevas reglas. La omnipotencia narcisista se va limando cuando choca con otro narcisismo más maduro, flexible y dialogante, potente pero no agresivo, ni defensivo, 
ni cuestionado; simplemente honesto, cooperador, responsable. Un poco el que tratamos en la UCA de mostrar a Lena, en cada visita que nos viene a sesión, con y sin cita programada.

CHRISTOPHER BOLLAS (nacido en 1943) es el discípulo de Winnicott que mejor desarrolla estos puntos, ya que llega a categorizar al terapeuta como "objeto transformacional" del self del paciente, gracias a cuya identificación y relación estrecha, en forma de transferencia recíproca, ambos Sí mismos se van modulando el uno con el otro.

De hecho, el falso self se caracteriza por ser conservador y repetitivo siempre, vacío, omnipotente desde la represión, miedoso al cambio, defendido en la negación y el desapego hacia lo diferente. El verdadero self sobrevive inmaduro, parapetado detrás del falso que es quien se adapta al entorno y consigue ganar la aprobación vital de los otros; sin embargo, este self genuino es por naturaleza emergente, creativo, empático y sociable: tiene suficiente fuerza libidinal para crecer por sí mismo cuando las condiciones del exterior -terapéutico y más tarde vivencial- permiten un desarrollo factible, seguro y espontáneo.

Bollas también afirma que el self es "objeto de nosotros mismos", de modo que nos tratamos en nuestro interior como fuimos tratados por los objetos parentales. La terapia no es otra cosa que explorar, como si de un juego se tratase, todas las aristas del self del sujeto, las positivas y las dolorosas, las que se pueden enseñar y las que se quieren ocultar hasta a la misma conciencia; y en este espacio intersubjetivo alcanzar poco a poco la transferencia al ambiente real, la cual radica en la emergencia de lo sano.

JORGE GARCÍA BADARACCO (1923-2010) también habla al respecto de la "virtualidad sana" que siempre albergamos en nuestro self, y que para hacerlo surgir a la superficie no vale otra actitud que la de creer en él, apostar por él, hacerlo valer, imaginarlo y darle la confianza de existir en la realidad cotidiana. Para este autor, el análisis tiene el fundamento de "creer para ver" y no "ver para creer"; es decir, no se trata de ver lo que ya existe en el otro, sino de adivinar lo que está oculto y potencial (virtual) para que pueda desarrollarse con libertad.

HEINZ KOHUT (1913-1981): Del fundador de la Psicología del Self sólo quiero destacar el énfasis que establece en los objetos parentales como objetos arcaicos y primarios del self, los cuales son necesariamente idealizados por el bebé para lograr la mínima cohesión y supervivencia del Yo, que permita sostener la libido primitiva fragmentada. La asimilación de esta imago parental idealizada crea el ideal del Yo, crítico, omnipotente, censor -Kohut sigue aquí la teoría freudiana-, y el self trata de imitar este modelo proyectado en el 
exterior, copiado internamente, fruto del cual deviene el llamado "self grandioso" (núcleo del narcisismo).

Para este autor el proceso de introyección del objeto parental arcaico siempre es idealizado, independientemente de las cualidades reales de los padres, aunque éstos sean figuras competentes y realistas. La idealización implica una distorsión, y va pareja de la "autoidealización" que es el mecanismo narcisista característico, tanto mayor cuanto menos investidura objetal haya, y más se dirija esta libido al Yo, por fracaso parental real u otro motivo.

El terapeuta, en consecuencia, ha de suplir las deficiencias originales de los objetos del self, primero de los maternales-arcaicos -funciones de fusión y cohesión- para luego, si el análisis lo permite, los objetos paternales -ideales normativos, límites, interacciones con objetos externos-. Se pretende corregir la deficiente especularización del pasado, alimentando la autoestima del paciente no desde la artificialidad, la compasión o nuevas idealizaciones, sino desde la empatía, la aceptación positiva incondicional, los modelos saludables de identificación...; en suma el self genuino de ambos.

En consecuencia, en las terapias con pacientes adictos primero se trata de alimentar gradualmente un self estable, sereno y separado para que el sujeto pueda sobrevivir cohesionado y seguro en el ambiente relacional, para más tarde poder acordar con él los límites y actitudes coherentes respecto a los consumos, valores, intereses o consecuencias; de nada vale empezar con la psicoeducación y las normas de salud con Lena, si su Yo no es capaz de sostenerse en los impulsos ni en los vínculos estrechos con los objetos de su entorno.

De ahí que la metáfora principal de Kohut no sea la trágica del Edipo freudiano, sino la dramática y positiva -con final feliz- del viaje de Ulises: primero saliendo del hogar hacia Troya, la participación inteligente y leal del héroe en aquella guerra, con victoria y regreso posterior; un retorno duro pero fructuoso a su tierra de Ítaca, llegando a ésta como un aparente desconocido, luego identificándose por medio de una proeza, que además barre de su camino a los rivales y se reencuentra plenamente con Penélope. La esposa / madre además había estado durante todos estos años aguardándolo, tejiendo de día y destejiendo de noche el tapiz de la vida al que otros autores intersubjetivos han recurrido para simbolizar la psicopatología.

Menciono aquí a OTTO KERNBERG (nacido en 1928) simplemente para señalar las diferencias esenciales con Kohut al respecto de la conceptualización y abordaje de la misma psicopatología borderline. Kernberg, fiel representante actual de las relaciones objetales estructurales, es tan relacional como biológico, pulsional, y para él el self grandioso siempre 
se constituye como algo deficitario y patológico ("narcisismo maligno", defensivo, irreal), lo mismo que el proceso de idealización. La psicoterapia se va a centrar en la interpretación constante y la elaboración de límites con el paciente, más que en reparación empática alguna de afectos y relaciones vinculares. Esta visión del narcisismo es kleiniana, deficitaria, pulsional, frente al resto de autores relacionales que estamos recorriendo, y que luego confluirán en la perspectiva del mismo Fonagy y su MBT.

Termino con los teóricos actuales del Psicoanálisis Relacional propiamente dicho, que son los llamados autores intersubjetivos: STEPHEN MITCHELL (1946-2000), ROBERT STOLOROW (nacido en 1942), DONNA ORANGE (nacida en 1944), GEORGE ATWOOD, BERNARD BRANDCHAFT (1917-2013), etc. Todos ellos defienden el paradigma postcartesiano, el cual deja atrás la "mente aislada" y categórica (res cogitans separada de la res extensa, lo mental distinto del cuerpo, el sujeto del objeto, el Yo de los otros) para abanderar la "matriz relacional" constituida por el self + los objetos + las interacciones a múltiples bandas, transicionales, donde sujetos y objetos se funden como bandas de Moebius en términos postmodernos, constructivistas. Ya no existen partes interna y externa, sino que - como las bandas aludidas- una cara tan pronto se vuelve otra como se difumina, sin límites claros entre los elementos de este tapiz de Penélope o matriz relacional.

El rol del terapeuta es el de "pontífice", es decir, un "hacedor de puentes" que traza conexiones entre los distintos puntos y nodos que emergen de la matriz, del conjunto de self y objetos que se está jugando a explorar en el análisis. Es éste un "psicoanálisis emancipatorio" que se levanta de las reglas y principios ortodoxos del pasado -asociación libre, atención flotante, abstinencia, neutralidad- para abolir toda reglamentación de categorías, técnicas, normas y condiciones, en una nueva phronesis (arte) que deja atrás las limitaciones de la techné (técnica o método analítico) para constituirse en nuevo marco de relación entre dos personas que sufren, y que se ayudan una a la otra desde diferentes posiciones genuinas.

La hermenéutica que corresponde ya no puede ser la de la sospecha freudiana: buscar continuamente síntomas, huellas deficitarias, daños y resistencias para definirlas y abolirlas. La nueva "hermenéutica de la confianza" llama continuamente a ésta para erigir defensas y resistencias "heroicas", cuya existencia no revela un defecto o problema psíquico, sino la singularidad de una supervivencia del Yo en un panorama difícil, insuficiente, condicionado por afectos fallidos.

El nuevo paradigma relacional, post-cartesiano, intersubjetivo, tiene como herramienta clínica básica a la misma relación terapéutica y analítica, entre paciente y 
terapeuta -entre las personas enteras y auténticas del paciente y su terapeuta-, el play genuino que se mueve entre estos dos Sí mismos para trazar nuevos nexos y significados donde los anteriores se revelan sufrientes y dolorosos. La otra cara de misma moneda es la ética clínica, fundamentada en la responsabilidad de uno con el otro, en la aceptación positiva e incondicional del otro; en la acogida, comprensión y validación de la singularidad del otro que los autores intersubjetivos ejemplifican con la tienda del desierto, la que hospeda al peregrino y le sirve de descanso. Esta responsabilidad conforma también la respuesta íntima, coherente de uno a la demanda del otro, sobre todo cuando se palpa el sufrimiento, tan presente unas veces -y tan negado otras con el goce- en el mundo de las adicciones.

\section{¿PERO QUÉ ES LA MBT?}

Después de todo este recorrido de temas, autores y teorías, ¿qué queda de la Terapia Basada en la Mentalización de Fonagy \& cols.? Podemos responder que resulta ser una aplicación práctica, emergente e intersubjetiva de los principios anteriores a casos como el de Lena, en un formato diferente -eso sí- al de la UCA de la salud mental pública, donde se permita un setting de mayor abordaje, continuidad en las sesiones con tiempo suficiente durante la misma semana, sin presión de agenda ni disparidad de funciones en el curso de la propia terapia; lo cual tantas veces descoloca al paciente y resta posibilidades a una relación terapéutica efectiva.

Para terminar, me gustaría mencionar sendas entrevistas a Peter Fonagy y Mary Target en Internet (Vimeo), que constituyen a mi juicio buenas síntesis de los fundamentos y pragmatismos de la intervención clínica MBT para pacientes TLP, complicados la inmensa mayoría de las veces -como vemos en Lena- con adicciones a tóxicos. La reseña que se puede hacer de ellos, y que deja abierta esta sesión clínica transcrita en publicación, es la siguiente.

PETER FONAGY: Los métodos tradicionales analíticos se quedan muy cortos para tratar a pacientes complicados, con síntomas graves de impulsividad, autolisis, fuertes alteraciones del ánimo y escisión en el self. La "mentalización" conecta con el concepto freudiano de "representación", y es lo que en otras escuelas se denomina "simbolización"; pero para prevenir confusiones filosóficas se ha optado por un término convergente con la psicología cognitiva y experimental actual. Este método fue descubierto casi accidentalmente, mientras el equipo estudiaba a pacientes adolescentes con "diabetes lábil": las chicas eran inteligentes y conscientes de su enfermedad orgánica, pero preferían tirar la insulina por el lavabo e incumplían -en secreto- las pautas médicas. En realidad nadie hasta entonces las 
había escuchado en sus pensamientos y emociones íntimas, lo mismo que a otros tantos pacientes autolíticos y borderline, pobremente comprendidos por sus terapeutas.

Fonagy y su equipo descubrieron que simplemente escuchando a estas pacientes, sus motivaciones, ideas, afectos... podían empatizar con ellas e ir más allá del trato previo, percatándose de que ellas se entendían mal a sí mismas, lo mismo que malinterpretaban las intenciones del entorno. Resultó que muchas de estas chicas habían sido traumatizadas de niñas, con fuertes abusos y humillaciones, que no habían podido superar. El apego que tuvieron en la primera infancia no les permitió aprender correctamente la Teoría de la Mente, de modo que las agresiones que recibían no eran adecuadamente representadas: estas pacientes aprendieron a no entender las acciones de los otros en términos de motivación, sino de simple acción literal, bruta. Fonagy teoriza que, con figuras de apego agresivas o arbitrarias, pensar o empatizar esos estados mentales resulta particularmente doloroso para el niño, y por eso evita hacerlo, concentrándose sólo en el significado literal de la conducta que en ese momento actúa. Así se van desarrollando en el self carencias de empatía, de asertividad... y los rasgos límite y/o antisociales.

Este modo de funcionamiento psíquico y social no puede cambiar hasta que los pacientes no entablan una relación estable con alguien que les demuestra una y otra vez que sí está interesado en los sentimientos y pensamientos subjetivos, y no sólo en el significado bruto de las acciones. Los pacientes límite han desconocido siempre el rol de agentes de las interacciones que causan en el entorno, de modo que provocan aquello que continuamente también reciben, y que es básicamente traumático para ellos y los demás. Si consiguen darse cuenta, sesión a sesión, de esta dinámica amplificada, "mentalizada", el resultado será distinto también en cuanto a feedback: la vida pasará de restringirse a reacciones e impulsos literales, a complicarse con nuevos contenidos mentales de representaciones, intenciones, motivaciones de los otros significativos, y de sí mismos. Las interacciones pasarán a ser mucho más difusas, ambiguas y posibles; de modo que no necesitarán proyectar la parte de sí mismos que identifican con el agresor, porque se pensarán / entenderán mejor a sí mismos y al analista, y poco a poco lo irán extendiendo a más personas. El self se irá enriqueciendo y cohesionando, evolucionando de la fragmentación y escisión, en una suerte de mayor habilidad social y cognitiva.

El autor reconoce cierta vergüenza a la hora de explicar lo que en la clínica trabajan con los TLP, tan de sentido común que resulta elemental: la conversación con estos pacientes se limita al tema de la mente, los pensamientos y sentimientos del aquí y ahora, la relación presente del sujeto con el analista y otras figuras significativas, actuales. "Focalizar, elaborar, corregir, clarificar, transformar lo intolerable en tolerable, y sobre 
todo ser astuto y exquisitamente sensible para oír e identificar cuando el paciente ha perdido su capacidad de mentalizar, cuando hablan en términos concretos, confunden apariencia con realidad, lo que sienten con cómo son las cosas realmente allá afuera; si, dada su dificultad para mentalizar, confabulan acerca de los estados mentales del otro; cuando elaboran modelos complicados de los estados mentales en los demás, o en ellos mismos, que es lo que estos sujetos hacen para compensar la falta de experiencia de mentalización real".

De modo que si, durante el transcurso de la sesión, aparece un momento de "pseudomentalización" -confabulación, "modo como si" o pretend mode, "funcionamiento teleológico" porque lo único percibido es lo material-, en ese instante el analista ha de intervenir -dramáticamente incluso- para interrumpir el proceso, sin admitir esta forma de pensar errónea; aunque el rapport sea favorable el síntoma no se puede perpetuar en la terapia. Acto seguido, paciente y terapeuta focalizan la atención, emoción y cognición del otro en la buena mentalización; en aquella motivación probable del otro cercano -incluido el analista-, validando y celebrando las representaciones cognitivas verosímiles, y más tarde clarificando y amplificando las cosas conforme la relación se afianza y la Teoría de la Mente de la persona se va desarrollando. Poco a poco llegará el momento de acercarse a las áreas más sensibles y dolorosas del sujeto, las más cercanas a su trauma infantil donde justamente la capacidad de mentalización fracasa estrepitosamente.

Y para ello resulta fundamental la solidez y calidez de la relación terapéutica, que puede llevar años de psicoterapia semanal. La cual Fonagy destaca que funciona precisamente por esto: por ese espacio seguro de relación interpersonal donde el paciente se siente pensado, "nos ve como un otro pensando en él de manera clara y coherente, y puede empezar a internalizar una imagen de sí mismo como un ser que piensa y siente, una capacidad que no pudieron desarrollar en la infancia temprana. Y esto pasa a formar el núcleo del sentimiento del self, que sustentará la posibilidad de mentalizar en situaciones más complejas que tienen lugar fuera de la consulta clínica".

MARY TARGET: La función del analista en consulta es aportar al paciente una versión de aquello que los padres debieron proveerle en su infancia temprana y no pudieron, como medio para reparar en el seno de la relación segura las deficiencias del vínculo de apego (que para la autora constituye un motor pulsional comparable a la libido o la pulsión agresiva) por medio del mirroring -espejamiento o especularización-. Éste le permite al paciente, viendo reaccionar empáticamente a su terapeuta, reconocer en ese momento y lugar lo que está sintiendo, de una forma clarificada, simbolizada, y no de la forma bruta o saturada en que habitualmente lo hace. Durante los primeros años del análisis se trabaja 
esta función primaria, involucrando al paciente a contener mejor su conducta y volverse más consciente de los estados mentales, sobre todo de cómo se interconectan unos con otros y con los distintos desarrollos propios y ajenos; sólo más adelante cabrá hacer interpretaciones de estas tales conductas, en términos simbólicos.

El analista se implica personalmente con cada reflejo o "mirroring" hacia el paciente, de modo que al clarificar algún contenido, emoción, pensamiento, etc. "inevitablemente incluye algo de su propia actitud con respecto a aquel sentimiento": las opiniones y actitudes del terapeuta se hacen evidentes en la sesión, y son parte del trabajo analítico con el paciente, de la interacción y procesamiento de estados mentales y afectivos. Target explica en un caso clínico cómo una paciente TLP estaba tan interesada en ella como persona y viceversa, y esa mujer trataba de obtener control sobre sí misma y relacionarse con los demás a través de hacer consciente aquello que estaba sintiendo con su analista, y también ésta era consciente de la actitud con respecto a los sentimientos y valores de su paciente. En pocas palabras, el terapeuta implicado siente verdadera empatía por el sufrimiento del paciente, y se lo transmite como clave relacional de la psicoterapia, como una validación auténtica que va mucho más allá de palabras tranquilizadoras: el sujeto llega a conocer la manera en que -a lo largo de los años de terapia y tantas escenas compartidas en consulta- está realmente afectando a la vida del analista, le importa más allá de ser parte de su trabajo.

He aquí la clave final que aporta la autora sobre el acompañamiento terapéutico de estos pacientes "incomprensibles" y "descontrolados" -límites, destructivos y adictos como Lena-: "el analista no es simplemente una "máquina reflejante" -reflecting machine-, sino que es una persona a la que le importa el paciente, tanto como persona que como analista". Los lectores juzgarán si esto no es plenamente relacional, intersubjetivo y emergente. El encuadre con Lena no permite de momento tanta estructura y continuidad de sesiones como establece la MBT, pero sí lo mueve el paradigma relacional y mi actitud con la paciente al respecto, remitiendo a la mentalización y yendo muchas veces más allá.

\section{REFERENCIAS}

Bateman, A. \& Fonagy, P. (2018). Tratamiento basado en la mentalización. Aperturas Psicoanalíticas, Revista de Psicoanálisis, 59 e31, 1-22.

Bermejo, P. (2008): La regulación afectiva, la mentalización y el desarrollo del self (reseña de los capítulos 1, 2, 5 y 11 del libro de Fonagy y cols de 2002). Aperturas Psicoanalíticas, Revista Internacional de Psicoanálisis, 30 (en html). 
Bollas, C. (1991). La sombra del objeto. Psicoanálisis de lo sabido no pensado. Buenos Aires: Amorrortu (original de 1987).

Fairbairn, W.R.D. (1978). Estudio Psicoanalítico de la Personalidad. Buenos Aires: Hormé.

Ferenczi, S. (1997). Sin empatía no hay curación. El Diario Clínico de 1932. Buenos Aires: Amorrortu.

Fonagy, P., Gergely, G. Jurist, E. \& Target, M. (2002). Affect regulation, mentalization and the development of the self. New York: Other Press.

García Badaracco, J.E. (1990). Comunidad Terapéutica Psicoanalítica de Estructura Multifamiliar. Madrid: Julián Yébenes Editores.

González Guerras, J. (2008). Psicoanálisis y toxicomanías. Clínica E Investigación Relacional, 2 (1): 146-164.

González Guerras, J. (2011). "Yo solo, por ahí, lleno de mocos". Reflexiones sobre el tratamiento relacional de la adicción grave. Clínica E Investigación Relacional, 5 (3): 525-542.

Kohut, H. (1986). ¿Cómo cura el análisis? Buenos Aires: Paidós (original de 1984).

Mitchell, S.A. (1990). Conceptos relacionales en psicoanálisis: Una integración. México: Siglo XXI (original de 1988).

Orange, D. (2011). "La actitud de los héroes". Bernard Brandchaft y la hermenéutica de la confianza. Clínica e Investigación Relacional, 5 (3): 507-515.

Orange, D., Atwood, G.E. y Stolorow, R.D. (2012): Trabajando intersubjetivamente. Contextualismo en la práctica psicoanalítica. Madrid: Ágora Relacional (original de 1997).

Pichón Rivière, E. (1985). Teoría del vínculo. Buenos Aires: Nueva Visión.

Stolorow, R.D. y Atwood, G.E. (2004). Los contextos del ser. Las bases intersubjetivas de la vida psíquica. Barcelona: Herder (original de 1992).

Winnicott, D.W. (1971). Realidad y Juego. Barcelona: Gedisa.

Winnicott, D.W. (1992). Los procesos de maduración y el ambiente facilitador. Barcelona: Paidós.

Web (actualizado el 28/1/19): https://vimeo.com/77237767 (vídeo de Peter Fonagy); https://vimeo.com/163673216 (vídeo de Mary Target); https://youtu.be/NVgkgbEogxc (vídeo de Antonio Block sobre Teoría de la Mente).

Zegarra-Valdivia, J. \& Chino Vilca, B. (2017). Mentalización y teoría de la mente. Revista de Neuropsiquiatría 80 (3): 189-199

Original recibido con fecha: 31/01/2019 Revisado: 15/02/2019 Aceptado: 30/03/2019 